Article

\title{
Prevalence of Psychological Distress and Associated Factors in Nursing Students during the COVID-19 Pandemic: A Cross-Sectional Study
}

\author{
Fumiya Tanji ${ }^{1, *(1)}$ and Yuki Kodama ${ }^{2}$ \\ 1 Faculty of Nursing, Japanese Red Cross Akita College of Nursing, Akita 010-1490, Japan \\ 2 Faculty of Nursing, Tokyo University of Information Sciences, Chiba 265-8501, Japan; \\ y3kodama21@rsch.tuis.ac.jp \\ * Correspondence: tanji@rcakita.ac.jp; Tel.: +81-18-829-4000
}

check for

updates

Citation: Tanji, F.; Kodama, Y. Prevalence of Psychological Distress and Associated Factors in Nursing Students during the COVID-19 Pandemic: A Cross-Sectional Study. Int. J. Environ. Res. Public Health 2021, 18, 10358. https://doi.org/10.3390/ ijerph181910358

Academic Editors: Mariagrazia Di Giuseppe and Ciro Conversano

Received: 27 August 2021

Accepted: 29 September 2021

Published: 1 October 2021

Publisher's Note: MDPI stays neutral with regard to jurisdictional claims in published maps and institutional affiliations.

Copyright: (c) 2021 by the authors. Licensee MDPI, Basel, Switzerland. This article is an open access article distributed under the terms and conditions of the Creative Commons Attribution (CC BY) license (https:// creativecommons.org/licenses/by/ $4.0 /)$.

\begin{abstract}
Little is known about psychological distress and its associated factors during the COVID-19 pandemic among nursing students, especially during the initial spread. The present study aimed to investigate the prevalence of psychological distress among Japanese nursing students after the first semester of 2020 with shifted classes and practice online. Furthermore, we examined whether factors such as health issues and resilience were associated with psychological distress. The data were obtained from a cross-sectional, self-administered questionnaire survey at a Japanese nursing college from September to November $2020(n=289)$. We collected data such as sociodemographic variables, medical history, insomnia, and resilience (Bidimensional Resilience Scale). Psychological distress was measured using the $\mathrm{K} 6$ scale (scores $\geq 5$ ). The prevalence of psychological distress was $58.5 \%$. The multivariate Poisson regression analysis found a negative association between innate resilience factors, and positive associations between medical history, insomnia, and psychological distress. The present study showed that more than half of the study participants experienced high levels of psychological distress. Our results suggest the importance of monitoring mental health among nursing students, focusing not only on health issues, but also personality components such as innate resilience during the prolonged COVID-19 pandemic.
\end{abstract}

Keywords: psychological distress; resilience; insomnia; nursing student; COVID-19

\section{Introduction}

The coronavirus disease 2019 (COVID-19) pandemic first emerged in Wuhan, China, in December 2019, and it has since spread worldwide. As of 23 August 2021, there were more than 200 million confirmed cases and 4 million deaths worldwide [1], with approximately 1.3 million confirmed cases and 1500 deaths in Japan [2]. The COVID-19 outbreak forced countries around the world to initiate lockdowns or partially regulate behavior and has impacted educational settings, which have shifted from face-to-face classes to online classes [3]. These changes in educational methods have placed a burden on university students in developing infrastructure, acquiring digital skills, and feeling lonely due to thinning interpersonal relationships [4]. Therefore, university students have also experienced stress due to the sudden change in educational methods, in addition to the COVID-19 infection itself.

Among university students, those in fields such as nursing and medicine often face significant stress throughout their education $[5,6]$. These factors include extensive curricula, numerous academic requirements, and difficult examinations and assignments $[5,6]$. Before the COVID-19 pandemic emerged, a systematic review reported that the prevalence of psychological distress, such as depression and depressive symptoms, was $27.2 \%$ among medical students [7]. Recent studies soon reported the prevalence of moderate or severe psychological distress measured by the Kessler Psychological Distress Scale (K6) in the 
months after the COVID-19 pandemic emerged: $26.6 \%$ among Chinese medical science students [8] and 28.5\% among Japanese medical students [9]. When comparing the prevalence of psychological stress preceding the pandemic and following it, there seems to be little difference. However, another study reported that the prevalence of moderate or severe psychological distress measured by K6 was 19.7\% among university freshmen of various disciplines following the pandemic [10]. Thus, the prevalence of psychological distress may be higher among students in the medical science field than among non-medical science students. Fushimi reported that the number of students attending mental health consultations increased in the latter part of 2020 [11], which implies that the prevalence of psychological stress may have increased. However, there are few reports on the prevalence of psychological stress among medical science students several months after the continued changes in educational methods due to the COVID-19 pandemic. The present study conducted a web-based survey among nursing students in the second semester of 2020, after they had taken classes and practiced online in the previous semester.

Previous studies have shown related factors, such as health issues (e.g., chronic disease as a COVID-19 infection risk, and insomnia) and socioeconomic status (SES), for psychological distress following the COVID-19 pandemic [12,13]. In addition, when a social stress event such as COVID-19 occurs, an individual's personality influences their mental health. For example, the impact of the 1997-1998 economic crisis on the completed suicide risk differed according to personality subscales; suicide risk increased among those with higher neuroticism after the economic crisis, whereas there was no such association for other personality subscales [14]. This is due to the ability of a specific personality type to cope with stress and hardship.

The ability of an individual to bounce back or recover from stress is known as resilience [15]. There are many scales to measure resilience, but the Bidimensional Resilience Scale (BRS) developed by Hirano et al. classifies it into two dimensions: innate and acquired factors [16]. This scale was constructed using the Temperament and Character Inventory (TCI) scale developed by Cloninger et al. as an external criterion [17]. They divided personality into two dimensions: temperament, which is independently heritable, and character, which is acquired. Innate resilience factors of the BRS are strongly related to temperament, and the acquired resilience factors of the BRS are related to character [16]. It is well known that resilience is associated with psychological distress $[18,19]$. To our knowledge, however, no study has examined whether this association involves innate or acquired resilience.

The present study aimed to investigate the prevalence of psychological distress and the factors associated with psychological distress among Japanese nursing students after taking classes and practicing online in the first semester of 2020. We included the learning environment, health issues, and resilience as associated factors.

\section{Materials and Methods}

\subsection{Study Design, Participants, and Data}

We conducted a cross-sectional, web-based, self-administered questionnaire survey at a nursing college in Akita, in northern Japan. Akita Prefecture in Japan is located in a suburban area and the number of people infected with COVID-19 is low compared to urban areas such as Tokyo. We conducted the survey anonymously from 25 September to 30 November 2020. During this period, the study participants were required to take hybrid classes (online and face-to-face), could not practice at hospitals but instead online or on campus, and had to limit unnecessary outings in their daily lives. We distributed the questionnaire to all undergraduate students regardless of year $(n=430)$, and a total of 293 students $(68.1 \%)$ participated in the survey. We excluded four respondents who had no psychological distress data. Thus, 289 participants were included in the analysis.

After obtaining written consent from the participants, we collected and used the data from the anonymous survey. This study was reviewed and approved by the Ethics Committee of the Japanese Red Cross Akita College of Nursing (approval number: 2020-113). 


\subsection{Use of Secondary Data}

To estimate the prevalence of psychological distress before the COVID-19 pandemic among people around the same age as the study participants (aged 20-24 years), we used aggregated data from the Comprehensive Survey of Living Conditions (CSLC) in 2019 as secondary data [20]. The CSLC has been conducted annually through small-scale and large-scale surveys every three years by the Ministry of Health, Labor, and Welfare of Japan [21]. The large-scale survey included a health questionnaire, with questions covering psychological distress. The number of participants aged 20-24 years in the 2019 CSLC was 4595, and 4481 participants responded to questions about psychological distress [20]. We estimated the prevalence of psychological distress before the COVID-19 pandemic using their data.

\subsection{Assessments}

\subsubsection{Sociodemographic Data}

Sociodemographic data were collected on the year in college, sex, medical history (presence or absence), residence type (living alone, or living with family or in university housing), type of entrance examination (recommendation or written exam), and cumulative grade point average (GPA) as a measure of academic performance.

Academic performance was measured using GPA for fourth-year students and a functional grade point average (f-GPA) for first-to-third-year students, calculated using the raw score (0-100), grade point (GP), and credits, where GP = (raw score-55)/10. The f-GPA is calculated as $\Sigma(\mathrm{GP} \times$ credit) $/ \Sigma$ credit and ranges from 0 to 4.5 (continuous variable). We classified the participants into three groups based on academic performance-specific tertiles: lower, middle, and higher.

\subsubsection{Psychosocial Factors}

We collected data on resilience, insomnia, concerns in college life (keeping up with classes, getting a job and proceeding to the next level of education, and friendship in college), subjective economic status (severe, normal, or affluent), and sense of fulfilment in college life (fulfilling or not fulfilling).

Resilience measured using the Bidimensional Resilience Scale (BRS) confirmed the validity and reliability of the data [16], which has been used in many studies [22,23]. The BRS comprises 21 items in two dimensions: 12 items for innate factors and 9 items for acquired factors. Each of the 21 items was assessed using three questions with five response levels, ranging from 1 (strongly disagree) to 5 (strongly agree). Thus, the total point scores of innate and acquired resilience factors ranged from 12 to 60, and from 9 to 45 , with higher scores indicating a greater impact for each factor. For each factor, we classified the participants into three groups according to tertiles: lower (12-39 points), middle (40-45 points), and higher groups (46-60 points) for innate factors; and lower (9-31 points), middle (32-35 points), and higher groups (36-45 points) for acquired factors.

Insomnia was measured using the Athens Insomnia Scale (AIS) [24,25]. The total score ranges from 0 to 24 . We classified participants with scores of $\geq 6$ as having insomnia and those with scores $\leq 5$ as not having insomnia [24].

Concerns in college life were assessed by asking the question, 'Do you have any concerns in your college life related to the following items: (1) keeping up with classes, (2) whether to get a job or to proceed to the next level of education as desired, or (3) friendship in college?' The participants were asked to choose one of the following four answers: 'many, some, few', and 'none'. For the above three items, we classified participants into two groups: presence (many or some) and absence (few or none).

\subsubsection{Psychological Distress}

Psychological distress was measured using the Kessler Psychological Distress Scale (K6) [26]. The Japanese version of K6 has been validated previously [27]. Total point scores ranged from 0 to 24 , with a higher score indicating severe psychological distress. 
In accordance with previous studies [28,29], we classified participants into three groups using cut-off points of $4 / 5$ and $12 / 13$ : low ( $0-4$ points), moderate (5-12 points), and severe (13-24 points).

\subsection{Statistical Analysis}

For baseline characteristics, we evaluated the proportion of each measurement and the mean (standard deviation (SD)) of each BRS score. We estimated the prevalence of psychological distress (low, moderate, and severe) among the current study participants and the 2019 CSLC participants' secondary data, then conducted a chi-squared test.

We assessed factors associated with psychological distress (K6 score $\geq 5)$ during the COVID-19 pandemic. First, multiple imputations were conducted for missing values of medical history, academic performance, living arrangement, insomnia, and BRS (acquired resilience factors) to create 10 output datasets. For these imputations, we used all variables as predictor variables. After the multiple imputation, we conducted a univariate Poisson regression analysis with a robust error variance to estimate the prevalence ratios (PRs) and $95 \%$ confidence intervals (CIs) using the following factors: medical history, residence type, type of entrance examination, GPA, innate resilience factor, acquired resilience factor, insomnia, concerns in college life (keeping up with classes, getting a job and proceeding to the next level of education, and friendship in college), subjective economic status, and sense of fulfilment with college life. Then, we simultaneously included variables for year at college and sex and performed a multivariate analysis including all factors, with $p<0.10$ identified in the univariate analysis. We also conducted a sensitivity analysis using a K6 score of $\geq 13$ as the dependent variable.

All statistical analyses were performed using IBM SPSS Statistics version 25 (IBM SPSS Software Group, Chicago, IL, USA). All statistical tests were two-sided analyses, and differences were considered significant at $p<0.05$.

\section{Results}

Table 1 shows the characteristics of all participants. The number of participants in each college year for the first, second, third, and fourth years was $85(29.4 \%), 85(29.4 \%)$, $58(20.1 \%)$, and $61(21.1 \%)$, respectively. The proportion of women was $91.7 \%(n=265)$. Among the participants who had concerns in college life, 139 (48.1\%) were concerned about keeping up with classes, $112(73.4 \%)$ were concerned about getting a job and proceeding to the next level of education, and $75(26.0 \%)$ were concerned about friendship in college. The number of participants with insomnia (AIS score $\geq 6$ points) was 105 (36.3\%). The mean (SD) BRS score for all participants was 41.97 (7.90) for the innate resilience factors and 32.90 (4.92) for the acquired resilience factors.

Table 2 compares the prevalence of psychological distress among study participants during the COVID-19 pandemic with that of Japanese people around the same age (aged 20-24 years) before the pandemic. The prevalence of psychological distress among study participants during the pandemic was $41.5 \%$ low, $46.0 \%$ moderate, and $12.5 \%$ severe. On the other hand, the distribution of psychological distress among Japanese people of the same age prior to the pandemic was $68.6 \%$ (low), $25.1 \%$ (moderate), and $6.3 \%$ (severe). Compared to the findings before the pandemic, the prevalence of psychological distress in this study's participants was approximately doubled in both the moderate and severe levels. The results of the chi-square test showed a significant difference in the prevalence of psychological distress during and before the COVID-19 pandemic $(p<0.001)$. 
Table 1. Characteristics of the study participants $(n=289)$.

\begin{tabular}{|c|c|c|c|}
\hline Characteristics & & $n(\%)$ & Mean $\left(S^{1}{ }^{1}\right)$ \\
\hline \multicolumn{4}{|l|}{ Year in college } \\
\hline & First & $85(29.4)$ & \\
\hline & Second & $85(29.4)$ & \\
\hline & Third & $58(20.1)$ & \\
\hline & Fourth & $61(21.1)$ & \\
\hline \multicolumn{4}{|l|}{ Sex } \\
\hline & Male & $24(8.3)$ & \\
\hline & Female & $265(91.7)$ & \\
\hline \multicolumn{4}{|l|}{ Medical history } \\
\hline & Presence & $85(37.1)$ & \\
\hline & Absence & $64(27.9)$ & \\
\hline & Missing & $10(4.4)$ & \\
\hline \multicolumn{4}{|c|}{ Type of entrance examination } \\
\hline & Recommendation & $23(10.0)$ & \\
\hline & Written exam & $204(89.1)$ & \\
\hline \multicolumn{4}{|c|}{ Academic performance } \\
\hline & Higher & $92(31.8)$ & \\
\hline & Middle & $96(33.2)$ & \\
\hline & Lower & $94(32.5)$ & \\
\hline & Missing & $7(2.4)$ & \\
\hline \multicolumn{4}{|c|}{ Living arrangement } \\
\hline & Living alone & $94(32.5)$ & \\
\hline & $\begin{array}{l}\text { Living with family or in university } \\
\text { housing }\end{array}$ & $194(67.2)$ & \\
\hline & Missing & $1(0.3)$ & \\
\hline \multicolumn{4}{|c|}{ Concerns in college life } \\
\hline \multicolumn{4}{|c|}{ Keeping up with classes } \\
\hline & Presence & $139(48.1)$ & \\
\hline & Absence & $150(51.9)$ & \\
\hline \multicolumn{4}{|c|}{$\begin{array}{l}\text { Getting a job and proceeding to the } \\
\text { next level of education }\end{array}$} \\
\hline & Presence & $112(73.4)$ & \\
\hline & Absence & $77(26.7)$ & \\
\hline \multicolumn{4}{|c|}{ Friendship in college } \\
\hline & Presence & $75(26.0)$ & \\
\hline & Absence & $214(74.0)$ & \\
\hline \multicolumn{4}{|c|}{ Subjective economic status } \\
\hline & Normal or affluent & $174(60.2)$ & \\
\hline & Severe & $115(39.8)$ & \\
\hline \multicolumn{4}{|c|}{ Sense of fulfilment with college life } \\
\hline & Fulfilling & $241(83.4)$ & \\
\hline & Not fulfilling & $48(16.6)$ & \\
\hline \multicolumn{4}{|l|}{ Insomnia $^{2}$} \\
\hline & Presence & $105(36.3)$ & \\
\hline & Absence & $183(63.4)$ & \\
\hline & Missing & $1(0.3)$ & \\
\hline \multicolumn{4}{|l|}{ Resilience $\left(\mathrm{BRS}^{3}\right)$} \\
\hline & Innate resilience factors & & $41.97(7.90)$ \\
\hline & Acquired resilience factors 4 & & $32.90(4.92)$ \\
\hline
\end{tabular}


Table 2. Comparison of psychological distress levels between study participants and the 2019 CSLC participants $(n=289)$.

\begin{tabular}{llcccc}
\hline & \multicolumn{4}{c}{ Psychological Distress (K6 ${ }^{2}$ Score) } \\
\cline { 3 - 6 } & $\begin{array}{c}\text { Low } \\
\mathbf{( 0 - 4 )}\end{array}$ & $\begin{array}{c}\text { Moderate } \\
\mathbf{( 5 - 1 2 )}\end{array}$ & $\begin{array}{c}\text { Severe } \\
\mathbf{( 1 3 - 2 4 )}\end{array}$ & $p$ \\
\hline During the COVID-19 pandemic \\
$\begin{array}{l}\text { Study participants (\%) } \\
\text { Pre-pandemic }\end{array}$ & $120(41.5)$ & $133(46.0)$ & $36(12.5)$ & $<0.001$ \\
& $\begin{array}{l}\text { 2019 CSLC } \\
\text { participants aged } \\
\text { 20-24 years (\%) }\end{array}$ & $3075(68.6)$ & $1123(25.1)$ & $283(6.3)$ & \\
\hline
\end{tabular}

${ }^{1}$ CSLC $=$ Comprehensive Survey of Living Conditions, ${ }^{2}$ K6 = Kessler 6-Item Psychological Distress Scale.

Table 3 shows the results of the univariate Poisson regression analysis with robust error variance after multiple imputations. The independent variables that showed significant positive associations with psychological distress (K6 score $\geq 5$ ) were medical history, concerns in college life (keeping up with classes, getting a job and proceeding to the next level of education, and friendship in college), subjective economic status, sense of fulfilment in college life, and insomnia $(p<0.05)$. The independent variables that showed a significant negative association with psychological distress were innate and acquired resilience factors $(p<0.001)$.

Table 3. Univariate Poisson regression analysis after multiple imputation $(n=289)$.

\begin{tabular}{lllcc}
\hline & PR $^{3}$ & \multicolumn{2}{c}{$\mathbf{9 5 \%} \mathbf{C I}^{\mathbf{2}}$} & $p$ \\
\hline Medical history & 1.48 & 1.22 & 1.78 & $<0.001$ \\
Type of entrance examination & 0.87 & 0.72 & 1.06 & 0.176 \\
Academic performance & 1.04 & 0.92 & 1.17 & 0.566 \\
Living alone & 0.97 & 0.78 & 1.19 & 0.751 \\
$\quad$ Concerns in college life & & & \\
$\quad$ Keeping up with classes & 1.42 & 1.16 & 1.73 & 0.001 \\
$\quad$ Getting a job and proceeding to the & 1.34 & 1.03 & 1.74 & 0.027 \\
$\quad$ next level of education & 1.45 & 1.21 & 1.74 & $<0.001$ \\
$\quad$ Friendship in college & 1.30 & 1.07 & 1.57 & 0.007 \\
Subjective economic status & 1.41 & 1.16 & 1.71 & $<0.001$ \\
Sense of fulfilment in the college life & 1.42 & 1.18 & 1.72 & $<0.001$ \\
Insomnia & & & & \\
Resilience (BRS ${ }^{1}$ ) & 0.97 & 0.96 & 0.98 & $<0.001$ \\
$\quad$ Innate resilience factors & 0.97 & 0.95 & 0.98 & $<0.001$ \\
$\quad$ Acquired resilience factors &
\end{tabular}

${ }^{1}$ BRS $=$ Bidimensional Resilience Scale,${ }^{2} \mathrm{CI}=$ confidence interval,${ }^{3} \mathrm{PR}=$ prevalence ratio.

Table 4 shows the results of the multivariate Poisson regression analysis with robust error variance after multiple imputations. Psychological distress (K6 score $\geq 5$ ) was used as the dependent variable, and factors with $p<0.10$ in Table 3 were used as independent variables. There were significant positive associations in medical history $(\mathrm{PR}=1.30 ; 95 \%$ CI, 1.07-1.59; $p=0.009$ ) and insomnia (PR = 1.26; 95\% CI, 1.06-1.50; $p=0.008)$. In terms of resilience, a significant negative association was found only in the highest group for the innate resilience factor score (PR $=0.70 ; 95 \% \mathrm{CI}, 0.53-0.92 ; p=0.011)$, while there was no association between the acquired resilience factors and psychological distress. 
Table 4. Multivariate regression analysis after multiple imputation $(n=289)$.

\begin{tabular}{|c|c|c|c|c|}
\hline \multirow[b]{2}{*}{ Year in college } & \multirow{2}{*}{$\begin{array}{c}\mathbf{P R}^{2} \\
1.03\end{array}$} & \multicolumn{2}{|c|}{$95 \% \mathrm{CI}^{1}$} & \multirow{2}{*}{$\begin{array}{c}p \\
0.512\end{array}$} \\
\hline & & 0.94 & 1.13 & \\
\hline Female & 0.92 & 0.70 & 1.21 & 0.543 \\
\hline Medical history & 1.30 & 1.07 & 1.59 & 0.009 \\
\hline \multicolumn{5}{|l|}{ Concerns in college life } \\
\hline Keeping up with classes & 1.21 & 0.995 & 1.47 & 0.057 \\
\hline $\begin{array}{l}\text { Getting a job and proceeding to the } \\
\text { next level of education }\end{array}$ & 1.25 & 0.96 & 1.62 & 0.100 \\
\hline Friendship in college & 1.15 & 0.97 & 1.37 & 0.113 \\
\hline Subjective economic status & 1.10 & 0.92 & 1.32 & 0.287 \\
\hline Sense of fulfilment in the college life & 1.18 & 0.98 & 1.42 & 0.074 \\
\hline Insomnia & 1.26 & 1.06 & 1.50 & 0.008 \\
\hline \multicolumn{5}{|l|}{ Innate resilience factors score (tertile) } \\
\hline Middle (40-45 points) & 0.82 & 0.65 & 1.03 & 0.082 \\
\hline Higher ( $\geq 46$ points) & 0.70 & 0.53 & 0.92 & 0.011 \\
\hline \multicolumn{5}{|l|}{ Acquired resilience factors score (tertile) } \\
\hline Middle (32-35 points) & 0.88 & 0.70 & 1.11 & 0.294 \\
\hline Higher ( $\geq 35$ points) & 0.90 & 0.70 & 1.15 & 0.401 \\
\hline
\end{tabular}

${ }^{1} \mathrm{CI}=$ confidence interval, ${ }^{2} \mathrm{PR}=$ prevalence ratio.

We conducted a sensitivity analysis using a $\mathrm{K} 6$ score of $\geq 13$ as the dependent variable (data not shown). There was a significant positive association between insomnia and psychological distress ( $\mathrm{PR}=2.42 ; 95 \% \mathrm{CI}, 1.29-4.55 ; p=0.007$ ). Although medical history and innate resilience factors showed similar associations with psychological distress, as shown in Table 4, there was no significant association. In contrast to the results in Table 4, there was a significant positive association between concerns about friendship in college and psychological distress $(\mathrm{PR}=2.03 ; 95 \% \mathrm{CI}, 1.13-3.66 ; p=0.019)$.

\section{Discussion}

In the present study, the prevalence of moderate and severe psychological distress among Japanese nursing students during the COVID-19 pandemic was 58.5\% (46\% for moderate and $12.5 \%$ for severe). This prevalence was approximately twice as high (both moderate and severe psychological distress) as that of the similarly aged Japanese participants in the 2019 CSLC secondary data. The present study showed that medical history, insomnia, and innate resilience factors were associated with psychological distress among Japanese nursing students during the COVID-19 pandemic. The results of the sensitivity analysis showed the same trends.

In previous studies of medical science students before the COVID-19 pandemic, the prevalence of depression or depressive symptoms had been reported to be $32.6 \%$ among Taiwanese nursing students and $27.2 \%$ among medical students worldwide [7,30]. In addition, previous studies reported that the prevalence of psychological distress a few months after the COVID-19 pandemic was $28.5 \%$ among Japanese medical students and $26.6 \%$ among Chinese medical science students [8,9]. These two studies assessed psychological distress (scores $\geq 5$ points) using the same K6 scale as in the present study. The present study, which was conducted after study participants had taken classes and practiced online in the first semester of 2020, showed approximately twice the prevalence of psychological distress (58.5\%) as the above two studies. This result suggests that prolonged changes in the learning environment and behavioral restrictions may have worsened psychological distress as well as increased its prevalence. Therefore, it is important to monitor the mental health of medical science students, including those in nursing, during prolonged stressful events such as COVID-19.

The present study showed an association between health issues such as chronic diseases, insomnia, and psychological distress during the COVID-19 pandemic. Patients with COVID-19 are more likely to have chronic disease, and those with chronic disease are more likely to die due to COVID-19 [31,32]. Younger people had longer media exposure 
and greater access to COVID-19 information, and those with a medical history were more likely to feel vulnerable to COVID-19, which might be associated with higher psychological distress [13,33]. The present study showed a strong association between insomnia and psychological distress in both the main and sensitivity analyses. Among the study participants, there were many comments that the shift from face-to-face classes and practice to online coursework resulted in an increase in assignments and a decrease in sleep time. In corroboration, Marelli et al. reported that the prevalence of insomnia increased among university students due to the introduction and continuation of online classes during the COVID-19 pandemic [12]. These changes in the learning environment may have influenced the association between insomnia and psychological distress. It might be important to screen and monitor students with health issues early on. In addition, it might also be necessary to improve and build upon current online education methods to reduce the burden on students.

In the present study, participants with higher innate resilience factors were significantly associated with lower psychological distress, whereas there was no association between acquired resilience factors and psychological distress. Among medical students, self-efficacy and self-esteem predicted psychological distress in the months after the COVID19 pandemic emerged [9]. Self-efficacy and self-esteem are known to promote resilience [34], which means that the resilience here is acquired. Another study reported that the association between COVID-19-related stressful experiences and acute stress disorder was mediated by resilience among university students [35], although resilience was not divided into innate and acquired factors. The acquired trait of resilience may affect how university students cope with acute stress immediately after a stressful event. Isobe et al. reported that only innate resilience factors were positively associated with self-rated health, and selfrated health was negatively associated with psychological distress among dental hygienists and dental hygiene students [22]. This previous study suggests that it is beneficial to focus on heritable traits of innate resilience factors, such as optimism and sociability, in order to maintain self-rated health status. Therefore, innate resilience factors may play a role in coping with stressful events, not only immediately after them, but also when stressful events are prolonged. Our results suggest that it may be important to focus on students' innate resilience (temperament) to maintain their mental health.

This study has some limitations. First, we had no data for specific responses to changes in the learning environment and types of chronic illnesses. Second, we had no primary data on resilience and psychological distress among study participants before the COVID-19 pandemic emerged, because we conducted a cross-sectional study at a single point in time after the pandemic. Psychological distress caused by the COVID-19 pandemic may have influenced resilience and insomnia (i.e., reverse causality). Third, this study was conducted at a single site. Not only between countries, but also within Japan, there would be differences in the COVID-19 infection rates among different regions and in the changes in educational methods across different universities. The study area is located in a suburban area, and the number of people infected with COVID-19 here is low compared to urban areas. However, the occurrence of just a few cases can easily lead to discrimination and hate, which may have made the people of the suburban area more sensitive to fears and anxiety of COVID-19 infection. The generalizability of our findings to Japanese nursing students may be limited.

\section{Conclusions}

The present study showed that the prevalence of psychological distress among Japanese nursing students was approximately twice as high as that among Japanese people of the same age prior to the COVID-19 pandemic. In addition, it was revealed that psychological distress may be affected by innate resilience factors, as well as health issues such as insomnia and chronic diseases. Our results suggest the importance of continuously monitoring mental health among nursing students during a prolonged COVID-19 pandemic. 
Further studies should prospectively explore the prevalence of psychological distress and its related factors.

Author Contributions: Conceptualization, F.T. and Y.K.; Methodology, F.T. and Y.K.; Validation, F.T. and Y.K.; Formal Analysis, F.T.; Investigation, F.T.; Resources, F.T.; Data Curation, F.T.; WritingOriginal Draft Preparation, F.T. and Y.K.; Writing—Review and Editing, Y.K.; Visualization, F.T.; Supervision, Y.K.; Project Administration, F.T.; Funding Acquisition, F.T. All authors have read and agreed to the published version of the manuscript.

Funding: This work was supported by the Japanese Red Cross Academy grant for research into nursing, care, and the Red Cross.

Institutional Review Board Statement: This study was conducted according to the guidelines of the Declaration of Helsinki and approved by the Ethics Committee of the Japanese Red Cross Akita College of Nursing (approval number: 2020-113 and date of approval: 28 July 2020).

Informed Consent Statement: Informed consent was obtained from all subjects involved in the study.

Data Availability Statement: The data presented in this study are available upon request from the corresponding author. The data are not publicly available because of privacy concerns.

Acknowledgments: We would like to thank all the study participants for their participation in this study. We also thank Hirohito Nanbu, Mayuko Ono, Noriko Abe, and Junko Nitta for their collaboration and support, and Kunimitsu Ashina for his technical assistance.

Conflicts of Interest: The authors declare no conflict of interest.

\section{References}

1. Coronavirus Disease (COVID-19) Pandemic. Available online: https://www.who.int/emergencies/diseases/novel-coronavirus2019 (accessed on 23 August 2021).

2. Situation Report. Current Situation in Japan. Available online: https://www.mhlw.go.jp/stf/covid-19/kokunainohasseijoukyou_ 00006.html (accessed on 23 August 2021).

3. International Association of Universities. The Impact of Covid-19 on Higher Education around the World. IAU Global Survey Report. Available online: https://www.iau-aiu.net/IMG/pdf/iau_covid19_and_he_survey_report_final_may_2020.pdf (accessed on 23 August 2021).

4. Radu, M.C.; Schnakovszky, C.; Herghelegiu, E.; Ciubotariu, V.A.; Cristea, I. The Impact of the COVID-19 Pandemic on the Quality of Educational Process: A Student Survey. Int. J. Environ. Res. Public Health 2020, 17, 7770. [CrossRef]

5. Almojali, A.I.; Almalki, S.A.; Alothman, A.S.; Masuadi, E.M.; Alaqeel, M.K. The Prevalence and Association of Stress with Sleep Quality among Medical Students. J. Epidemiol. Glob. Health 2017, 7, 169-174. [CrossRef]

6. Reeve, K.L.; Shumaker, C.J.; Yearwood, E.L.; Crowell, N.A.; Riley, J.B. Perceived Stress and Social Support in Undergraduate Nursing Students' Educational Experiences. Nurse Educ. Today 2013, 33, 419-424. [CrossRef]

7. Rotenstein, L.S.; Ramos, M.A.; Torre, M.; Segal, J.B.; Peluso, M.J.; Guille, C.; Sen, S.; Mata, D.A. Prevalence of Depression, Depressive Symptoms, and Suicidal Ideation among Medical Students: A Systematic Review and Meta-Analysis. JAMA 2016, 316, 2214-2236. [CrossRef] [PubMed]

8. Li, Y.; Wang, Y.; Jiang, J.; Valdimarsdóttir, U.A.; Fall, K.; Fang, F.; Song, H.; Lu, D.; Zhang, W. Psychological Distress among Health Professional Students during the COVID-19 Outbreak. Psychol. Med. 2021, 51, 1952-1954. [CrossRef] [PubMed]

9. Arima, M.; Takamiya, Y.; Furuta, A.; Siriratsivawong, K.; Tsuchiya, S.; Izumi, M. Factors Associated with the Mental Health Status of Medical Students during the COVID-19 Pandemic: A Cross-Sectional Study in Japan. BMJ Open 2020, 10, e043728. [CrossRef] [PubMed]

10. Fuse-Nagase, Y.; Kuroda, T.; Watanabe, J. Mental Health of University Freshmen in Japan during the COVID-19 Pandemic: Screening with Kessler Psychological Distress Scale (K6). Asian. J. Psychiatr. 2020, 54, 102407. [CrossRef] [PubMed]

11. Fushimi, M. Student Mental Health Consultations at a Japanese University and the Current State of Affairs on the Increase in Suicide Victims in Japan during the COVID-19 Pandemic. Psychol. Med. 2021. [CrossRef]

12. Marelli, S.; Castelnuovo, A.; Somma, A.; Castronovo, V.; Mombelli, S.; Bottoni, D.; Leitner, C.; Fossati, A.; Ferini-Strambi, L. Impact of COVID-19 Lockdown on Sleep Quality in University Students and Administration Staff. J. Neurol. 2021, 268, 8-15. [CrossRef]

13. Wang, Y.; Kala, M.P.; Jafar, T.H. Factors Associated with Psychological Distress during the Coronavirus disease 2019 (COVID-19) Pandemic on the Predominantly General Population: A Systematic Review and Meta-Analysis. PLoS ONE 2020, 15, e0244630. [CrossRef]

14. Tanji, F.; Kakizaki, M.; Sugawara, Y.; Watanabe, I.; Nakaya, N.; Minami, Y.; Fukao, A.; Tsuji, I. Personality and Suicide Risk: The Impact of Economic Crisis in Japan. Psychol. Med. 2015, 45, 559-573. [CrossRef] 
15. Smith, B.W.; Dalen, J.; Wiggins, K.; Tooley, E.; Christopher, P.; Bernard, J. The Brief Resilience Scale: Assessing the Ability to Bounce Back. Int. J. Behav. Med. 2008, 15, 194-200. [CrossRef]

16. Hirano, M. A Study of the Classification of Resilience Factors: Development of the Bidimensional Resilience Scale (BRS). Jpn. J. Personalit. 2010, 19, 94-106. [CrossRef]

17. Cloninger, C.R.; Svrakic, D.M.; Przybeck, T.R. A Psychobiological Model of Temperament and Character. Arch. Gen. Psychiatry 1993, 50, 975-990. [CrossRef]

18. Connor, K.M.; Davidson, J.R. Development of a New Resilience Scale: The Connor-Davidson Resilience Scale (CD-RISC). Depress. Anxiety 2003, 18, 76-82. [CrossRef] [PubMed]

19. Smith, G.D.; Yang, F. Stress, Resilience and Psychological Well-Being in Chinese Undergraduate Nursing Students. Nurse Educ. Today 2017, 49, 90-95. [CrossRef] [PubMed]

20. Comprehensive Survey of Living Conditions in 2019. Available online: https: / $/$ www.e-stat.go.jp/stat-search / files?page=1\& toukei $=00450061 \&$ tstat $=000001141126$ (accessed on 23 August 2021).

21. Health \& Social Statistics. Available online: https://www.mhlw.go.jp/english/database/db-hss/index.html (accessed on 23 August 2021).

22. Isobe, A.; Izumi, M.; Akifusa, S. Relationship between Resilience and Self-Rated Health in Dental Hygiene Students and Registered Dental Hygienists. J. Dent. Educ. 2018, 82, 1343-1350. [CrossRef] [PubMed]

23. Ueno, Y.; Hirano, M.; Oshio, A. The Development of Resilience in Japanese Adults: A Two-Wave Latent Change Model. Health Psychol. Open 2020, 7, 2055102920904726. [CrossRef] [PubMed]

24. Okajima, I.; Nakajima, S.; Kobayashi, M.; Inoue, Y. Development and Validation of the Japanese Version of the Athens Insomnia Scale. Psychiatry Clin. Neurosci. 2013, 67, 420-425. [CrossRef]

25. Soldatos, C.R.; Dikeos, D.G.; Paparrigopoulos, T.J. Athens Insomnia Scale: Validation of an Instrument Based on ICD-10 Criteria J. Psychosom. Res. 2000, 48, 555-560. [CrossRef]

26. Kessler, R.C.; Andrews, G.; Colpe, L.J.; Hiripi, E.; Mroczek, D.K.; Normand, S.L.; Walters, E.E.; Zaslavsky, A.M. Short Screening Scales to Monitor Population Prevalences and Trends in Non-Specific Psychological Distress. Psychol. Med. 2002, 32, 959-976. [CrossRef]

27. Furukawa, T.A.; Kawakami, N.; Saitoh, M.; Ono, Y.; Nakane, Y.; Nakamura, Y.; Tachimori, H.; Iwata, N.; Uda, H.; Nakane, H.; et al. The Performance of the Japanese Version of the K6 and K10 in the World Mental Health Survey Japan. Int. J. Methods Psychiatr. Res. 2008, 17, 152-158. [CrossRef]

28. Prochaska, J.J.; Sung, H.Y.; Max, W.; Shi, Y.; Ong, M. Validity Study of the K6 Scale as a Measure of Moderate Mental Distress Based on Mental Health Treatment Need and Utilization. Int. J. Methods Psychiatr. Res. 2012, 21, 88-97. [CrossRef]

29. Tanji, F.; Tomata, Y.; Zhang, S.; Otsuka, T.; Tsuji, I. Psychological Distress and Completed Suicide in Japan: A Comparison of the Impact of Moderate and Severe Psychological Distress. Prev. Med. 2018, 116, 99-103. [CrossRef]

30. Chen, C.J.; Chen, Y.C.; Sung, H.C.; Hsieh, T.C.; Lee, M.S.; Chang, C.Y. The Prevalence and Related Factors of Depressive Symptoms among Junior College Nursing Students: A Cross-Sectional Study. J. Psychiatr. Ment. Health Nurs. 2015, 22, 590-598. [CrossRef]

31. Williamson, E.J.; Walker, A.J.; Bhaskaran, K.; Bacon, S.; Bates, C.; Morton, C.E.; Curtis, H.J.; Mehrkar, A.; Evans, D.; Inglesby, P.; et al. Factors Associated with COVID-19-related Death Using OpenSAFELY. Nature 2020, 584, 430-436. [CrossRef] [PubMed]

32. Zhou, F.; Yu, T.; Du, R.; Fan, G.; Liu, Y.; Liu, Z.; Xiang, J.; Wang, Y.; Song, B.; Gu, X.; et al. Clinical Course and Risk Factors for Mortality of Adult Inpatients with COVID-19 in Wuhan, China: A Retrospective Cohort Study. Lancet 2020, 395, 1054-1062. [CrossRef]

33. Mazza, C.; Ricci, E.; Biondi, S.; Colasanti, M.; Ferracuti, S.; Napoli, C.; Roma, P. A Nationwide Survey of Psychological Distress among Italian People during the COVID-19 Pandemic: Immediate Psychological Responses and Associated Factors. Int. J. Environ. Res. Public Health 2020, 17, 3165. [CrossRef] [PubMed]

34. Ahmed, A.S. Post-Traumatic Stress Disorder, Resilience and Vulnerability. Adv. Psychiatr. Treat. 2007, 13, 369-375. [CrossRef]

35. Ye, Z.; Yang, X.; Zeng, C.; Wang, Y.; Shen, Z.; Li, X.; Lin, D. Resilience, Social Support, and Coping as Mediators between COVID-19-related Stressful Experiences and Acute Stress Disorder among College Students in China. Appl. Psychol. Health Well Being 2020, 12, 1074-1094. [CrossRef] 